ISSN 1817-3721, E-ISSN 1818-8745

Plant Tissue Cult. \& Biotech. 28(2): 191-199, 2018 (December)

CBangladesh Assoc. for Plant Tissue Culture \& Biotechnology

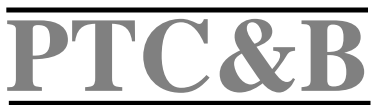

\title{
Elicitation of Bacoside Content Using Plant Growth Regulators in Cell Suspension Culture of Bacopa monnieri (L.) Wettst.
}

\author{
A.V. Kharde*1, S. V. Kore and M. B. Khetmalas ${ }^{2}$ \\ Dr. D. Y. Patil Biotechnology and Bioinformatics Institute, Dr. D. Y. Patil Vidyapeeth, \\ Pune-411033, MS, India
}

Key wards: Bacopa monnieri, Bacoside, Callus culture, Suspension, Elicitation

\begin{abstract}
Cell suspension culture is used for the optimization of plant growth regulators used for the elicitation of bacoside content of Bacopa monnieri (L.) Wettst. Callus induction was carried out on MS supplemented with 2, 4-D (0.5 mg/) by using leaf explants. For suspension culture MS liquid medium was supplemented with constant $\alpha$-naphthalene acetic acid $(0.5 \mathrm{mg} /)$ and casein hydrolysate $(1 \mathrm{~g} /)$ as well as the varied concentrations of 6-benzyleadenine, kinetin, thidiazuaron and chitosan. It was observed that bacoside production was increased by 6benzyleadenine $(0.5 \mathrm{mg} \Lambda)$, $\mathrm{Kn}(0.5 \mathrm{mg} \Lambda)$ and thidiazuaron $(0.25 \mathrm{mg} \Lambda)$ was 3.07 , 3.79 and $3.97 \mathrm{mg} / \mathrm{g}$, respectively. This indicates that lower concentration of growth regulator favor the bacoside enhancement under in vitro conditions, while chitosan affects the bacoside production in suspension culture. In this study thidiazuaron at $0.25 \mathrm{mg} /$ induces maximum elicitation of bacoside content i.e. $3.97 \mathrm{mg} / \mathrm{g}$.
\end{abstract}

\section{Introduction}

Bacopa monnieri L. Wettst is a medicinally important plant belongs to the family Plantaginaceae commonly known as Brahmi, found across the Indian subcontinent (Praveen et al. 2009). It grows in the humid climate, mainly distributed in damp and marshy tracts in the subtropical region of the Indian subcontinent. It requires a well drained, moist, sandy loam soil, rich in organic matter and grows well at a temperature from 30 to $40^{\circ} \mathrm{C}$ (Talukdar 2014). It is

*Author for correspondence: <ashokkharde@gmail.com>. ${ }^{1}$ MGM College of Agricultural Biotechnology, Gandheli, Aurangabad-431003, MS, India. 2Rajiv Gandhi Institute of Information Technology and Biotechnology, Bharati Vidyapeeth Deemed University, Pune - 411046, MS, India.

DOI: https://doi.org/10.3329/ptcb.v28i2.39678 
used as neuropharmacological drug against insomnia, insanity, depression, psychosis, epilepsy and stress (Elangovan et al. 1995, Tripathi et al. 1996 and Russo and Borrelli 2005). Brahmi is also used as brain tonic and blood purifier (Kala et al. 2006). The active ingredient found in Bacopa monnieri is triterpenoid saponin called bacoside, which is a complex mixture of glycosides of jujubogenin and pseudojujubogenin (Naik et al. 2010).

Brahmi has a good market demand due to its medicinal properties (Pravina et al. 2007). Estimated consumption of this drug in India is 1000 tons per year (Tripathi et al. 2012). More than $90 \%$ of plant material used by the industry is collected from the wild sources of which $70 \%$ involves unorganized harvesting. Natural regeneration requires specific habitat and also hampered by death of plant at two leaf stage (Chaplot et al. 2005). These factors possess a serious threat to the genetic stock and the biodiversity of medicinal plant. Due to the high demand and short supply of Bacopa monnieri, it is mostly adulterated species in Ayurvedic formulations. Bacopa monnieri is one of the important plant species in 32 prioritized medicinal plants for research and development by NMPB (Kala et al. 2006). The National Medicinal Plant Board (NMPB), Government of India and Technology Information Forecasting and Assessment Council (TIFAC) recommended immediate attention to seven medicinal plants, among which Bacopa monnieri prominently features and included in the category of highly endangered medicinal plants in India (Tripathi et al. 2012). Recent reports showed that there are variations in the bacoside content in the different parts of Brahmi plant and also the accessions collected from the various geographical locations (Naik et al. 2012), as well as there are seasonal variations in the bacoside content (Jain et al. 2013). Due to these reasons, there is an urgent need to find out the alternatives for the production of bacoside content of Brahmi to meet the huge market demands.

In present scenario plant cell culture is an attractive alternative for the production of secondary metabolites (Rao and Ravishankar 2002). Suspension culture offers an efficient mechanism for the enhancement of secondary metabolite production. It facilitates the incorporation of precursors in the media which provides the easy uptake of the nutrients by submerged cells than the other methods. It is also easy to harvest and scaling up the production of bioactive components in suspension culture. The possibilities of secondary metabolite production through plant cell culture have been demonstrated by various researchers (Alfermann et al. 1995, Fowler and Scragg 1998). Rahman et al. (2002) established cell suspension culture of Bacopa monnieri for first time, while Jain et al. (2013) reported enhancement of bacoside content in cell suspension culture in B. monnieri. Various strategies have been reported for the 
enhancement of secondary metabolite as well as biomass accumulation under in vitro conditions such as optimization of the medium and culture environment, selection of high secondary metabolite producing cell lines, use of organic supplements, elicitors and precursors in the medium (Parale et al. 2010 and Murthy et al. 2014). In plants secondary metabolite production influenced by various biotic and abiotic factors are called as 'elicitors'. Elicitation is a complex process and depends on many factors such as elicitor concentration, growth stage of the culture at the time of elicitor addition and exposure time with the elicitor (Sharma et al. 2014). Plant growth regulators are used as abiotic elicitors and play an important role in the enhancement of biomass and bacoside content under in vitro conditions.

Chaplot et al. (2005) reported the positive interactions of cytokinin (BA) and auxin (IAA) in Brahmi on biomass and bacoside production under in vitro conditions. Praveen et al. (2009) reported the use of various plant growth regulators viz. 6-benzyleadenine, $\mathrm{Kn}$ and thidiazuaron and Kamonwannasit et al. (2008) used 6-benzyleadenine, thidiazuron and chitosan for the enhancement of biomass and bacoside content in Brahmi.

Hence the present investigation is carried out with major objective to study the effect of plant growth regulators on the elicitation of bacoside content in Brahmi in cell suspension culture.

\section{Materials and Methods}

Bacopa monnieri (L.) Wettst. plants were collected from Paithan (19'28'33.9852”N and 75'22 45.0948”E), Aurangabad district in Maharashtra (India). Young leaf explants were selected from the healthy plantlets grown in the nursery for the experiment (Shrivastava and Rajani 1999). Excised leaf samples were washed and surface sterilized with 70\% ethanol for 2 - 3 sec then rinsed 3 - 4 times with sterile distilled water under aseptic conditions. Further antifungal treatment of $0.1 \%$ $(\mathrm{w} / \mathrm{N})$ mercuric chloride was given for five min (Parale et al. 2010) followed by 4 5 repeated washing with sterile distilled water. The surface sterilized leaf explants were incised to form wound using sterile surgical blades and used for the further experiment.

Surface sterilized leaf explants were inoculated on MS supplemented with 2, 4-D (0.5 mg $/)$ (Jain et al. 2013) in the glass culture tubes $(25 \times 150 \mathrm{~mm}$, Borosil). The $\mathrm{pH}$ of the medium was adjusted to 5.8 before autoclaving. Then cultures were incubated at $25 \pm 2^{\circ} \mathrm{C}$ with $16 \mathrm{hrs}$ light and $8 \mathrm{hrs}$ dark cycles, respectively. Induced callus was repeatedly sub cultured at every 21 days interval to produce friable callus. Friable callus was transferred to MS liquid medium (Bilore et al. 2016) supplemented with 2 , 4-D $(0.5 \mathrm{mg} \Lambda)$ to establish the suspension culture. 
Fine suspension culture was established by repeated sub culturing with continuous agitation. Suspension cultures were maintained in $50 \mathrm{ml}$ medium of $250 \mathrm{ml}$ conical flask and kept at $110 \mathrm{rpm}$ in dark conditions at $25 \pm 2^{\circ} \mathrm{C}$ on rotary incubating shaker (Rahaman et al. 2002 and Jain et al. 2013).

Media modifications were done with the aim to elicit bacoside production in cell suspension culture by using plant growth regulators as abiotic elicitors. The MS was supplemented with $\alpha$-naphthalene acetic acid (0.5 mg/) (Kamonwannasit et al. 2008) and casein hydrolysate ( $1 \mathrm{~g} /$ ) (Rahaman et al. 2002 and Jain et al. 2013) as constant, while the varied concentrations of elicitors such as 6benzyleadenine $(0,0.5,1.0,1.5$ and $2.0 \mathrm{mg} \Lambda), \mathrm{Kn}(0,0.5,1.0,1.5$ and $2.0 \mathrm{mg} \Lambda)$, thidiazuaron $(0,0.25,0.5,0.75$ and $1.0 \mathrm{mg} \Lambda)$ and chitosan $(0,25,50,75$ and 100 $\mathrm{mg}$ /). The $\mathrm{pH}$ of the suspension culture medium was adjusted to 6.0 before autoclaving (Naik et al. 2010). Suspension cultures of 6-benzyladenine and kinetin were incubated for 21 days, while chitosan and thidiazuaron for 7 days (Kamonwannasit et al. 2008).

After completion of incubation period cell suspensions were filtered by using Whatman filter paper (Grade No.1) to harvest the cells biomass from the culture. Filtered cells were washed with double distilled water to remove the traces of culture medium and the fresh cell weight (FCW) was recorded. The cells were dried in hot air oven at $60^{\circ} \mathrm{C}$ to achieve a constant dry cell weight (DCW). Dried cells were crushed and powdered with mortar and pestle. Powdered samples were soaked with water for $24 \mathrm{hrs}$ and squeezed out, followed by extraction with 95\% (v $/$ ) ethanol (Phrompittayarat et al. 2007). Standard curve was plotted with known quantities of standard bacoside (Sigma Aldrich ${ }^{\circledR}$ ) and detected at $278 \mathrm{~nm}$ using UV spectrophotometer (Saini et al. 2012). The samples were similarly treated and quantified by using standard curve.

All the experiments were arranged in completely randomized design. Each experiment consists of five treatments of different concentrations of plant growth regulators with four replications of each treatment (Panse and Sukhathme 1967). The results were analyzed by WASP 1.0 (www.ccari.res.in), using analysis of variance at $p=0.05$.

\section{Results and Discussion}

Bacopa monnieri leaf explants were injured and cultured on MS supplemented with 2, 4-D (0.5 mg/); were observed for the callus induction. A week after inoculation swelling was observed at the cuts and leaf attachment site followed by the callus initiation (Fig. 1a) and further covered the whole leaf explants (Fig. 1b). Similar pattern of callus initiation was reported in Arabidopsis thaliana (Ikeuchi et al. 2013), Bacopa monnieri (Kharde et al. 2017) and Celastrus paniculatus 
(Bilore et al. 2016). Callus proliferation was initiated due to the wound tissue produced in response to injury, by the progression of the mitotic cell cycle and the reacquisition of the cell proliferation ability of the differentiated plant cells (Ikeuchi et al. 2013). Friable callus was produced by repeated subcultures (Fig. 1c) and used for the development of suspension culture.
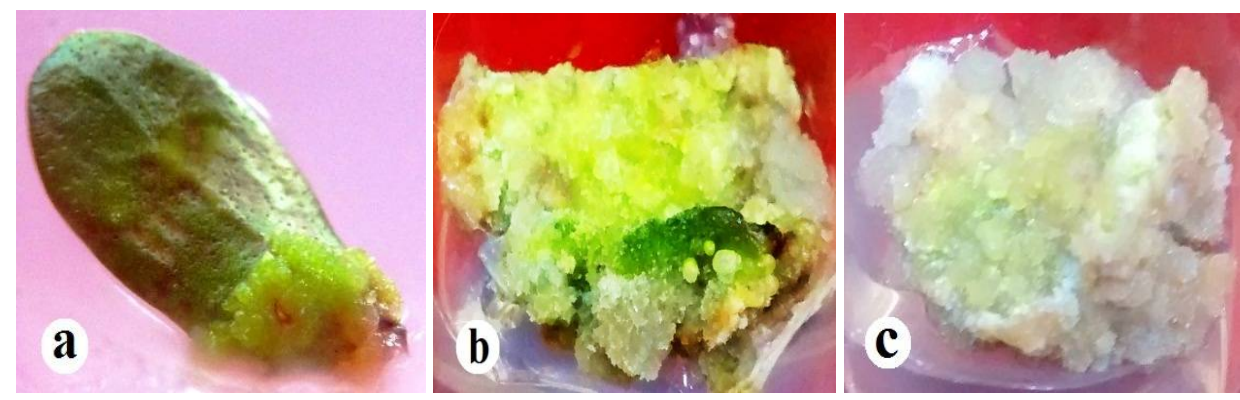

Fig. 1. Callus culture of Bacopa monnieri. (a) callus initiation from leaf, (b) proliferated callus after 4 weeks and (c) friable callus at the outer surface.

Present study on cell suspension culture of Bacopa monnieri was the first report in relation to the changes in color of the culture media, cell shape, biomass production and elicitation of bacoside content using plant growth regulators. Suspension cultures showed color changes from light white to pale yellow followed by yellowish brown at 7, 15 and 21 days after incubation, respectively (Fig. 2a-c). Similar type of color changes in cell suspension culture was reported by Ali et al. (2013) in Artemisia absinthium at different growth stages of cell culture, these changes in suspension might be due to the changes in $\mathrm{pH}$ of the medium, secretion of the phenols and other compounds, increased cell density
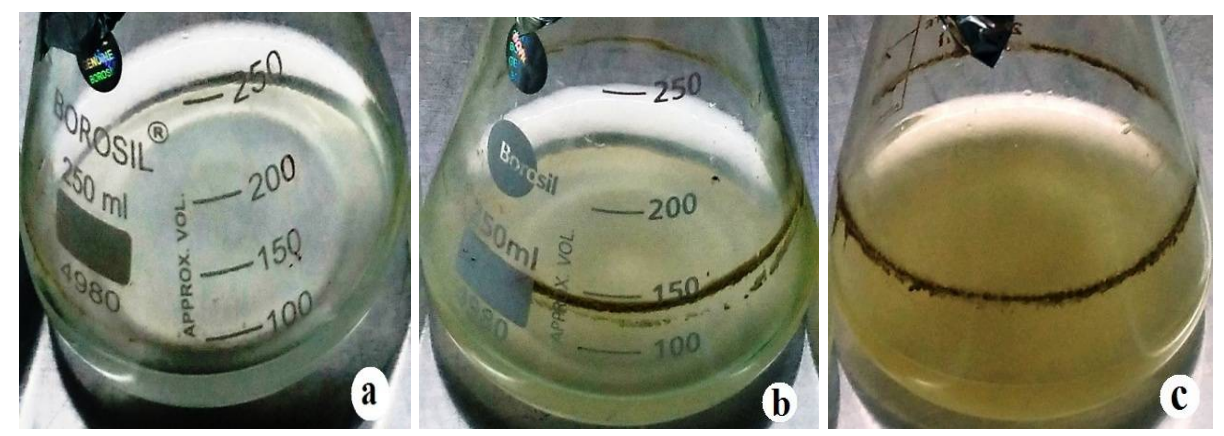

Fig. 2. Suspension culture of B. monnieri by suspending friable callus in MS liquid medium supplemented with 2, 4-D $(0.5 \mathrm{mg} \Lambda)$ on rotary incubating shaker at $110 \mathrm{rpm}$ in dark at $25 \pm 2^{\circ} \mathrm{C}$, (a) Cell suspension 7 days after sub culturing, (b) 15 days after subculturing and (c) 21 days after subculturing. 
and inadequate nutrients availability and due to the oxidation (Mustafa et al. 2011). In the present investigation the morphological variations were also observed in the Bacopa monnieri cells at different growth periods. In which, early stages of culture the clumped cells showed round cells, while elongated in later stages (Fig. 3a-c), such results were observed by Maraschin et al. (2002) in Mandevilla velutina cell culture and reported that the meristematic cells showed typical round shape in initial growth phases, whereas elongated cells in exponential phases.
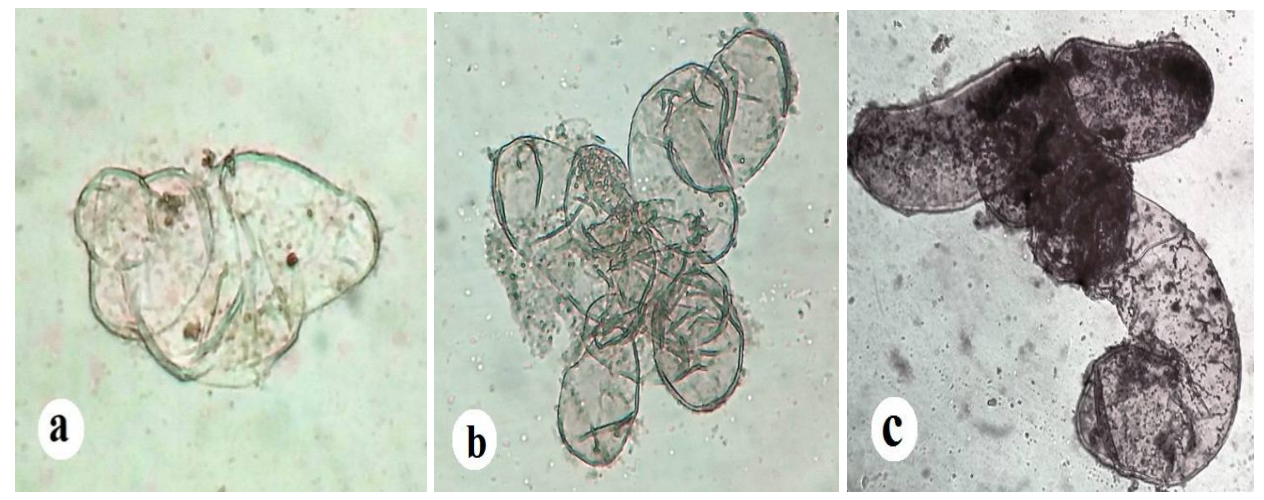

Fig. 3. Microscopic observations of B. monnieri cells in suspension culture (a-b), round cells in 7, 15 days and (c) elongated cells in 21 days after subculturing.

Cell biomass was influenced by the different concentrations of plant growth regulators in suspension culture. Present investigation reported enhancement in biomass of the cells i.e. 6-benzyleadenine at $0.5 \mathrm{mg} \Lambda$, kinetin at $1.5 \mathrm{mg} \Lambda$, thidiazuaron at $0.75 \mathrm{mg} /$ and chitosan at $100 \mathrm{mg} \Lambda$ produces significantly higher dry cell weight i.e. $0.56,0.32,0.54$ and $0.47 \mathrm{~g} \Lambda$, respectively (Fig. 4a-d). Previous reports by Praveen et al. (2009) showed the enhancement production of biomass as well as bacoside in in vitro regenerated shoots of Brahmi using different growth regulators in liquid medium over solid media. Bacoside elicitation was successfully achieved at lower concentrations of the growth regulators i.e. 6-benzyleadenine and $\mathrm{Kn}$ at $0.5 \mathrm{mg} /$ and thidiazuaron at $0.25 \mathrm{mg} /$ produces 3.07, 3.79 and $3.97 \mathrm{mg} / \mathrm{g}$ on dry weight basis, respectively (Fig. 4a-c) and significantly higher than the other levels of these growth regulators. While chitosan showed decrease in bacoside contents in suspension culture (Fig. 4d), Kamonwannasit et al. (2008) observed increased in the contents of bacoside in micropropagated plants. This might be due to the interactive effects of chitosan, NAA, caesin hydrolysate, $\mathrm{pH}$ and type of the culture used. 

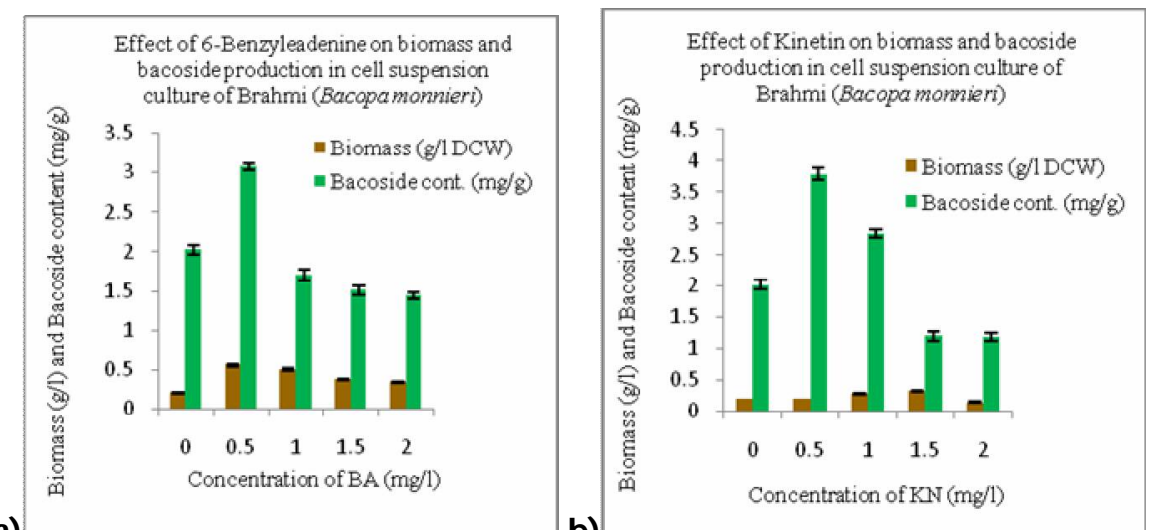

a)

b)
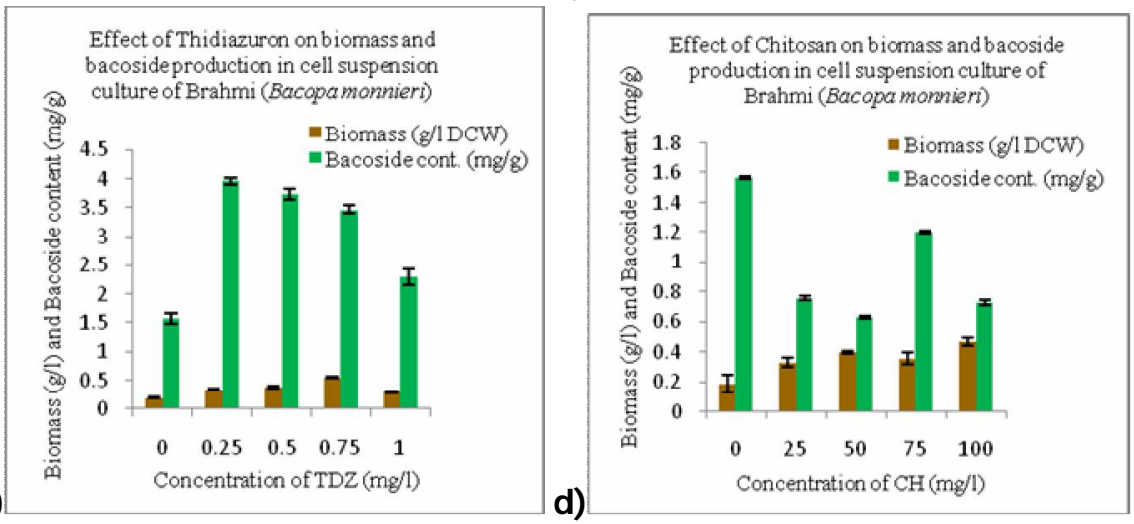

Fig. 4. Effect of 6-benzyleadenine (a), Kn (b), thidiazuaron (c) and chitosan (d) on biomass and bacoside production in Brahmi.

\section{Acknowledgments}

Authors are grateful to the Secretary, Mahatma Gandhi Mission, Aurangabad and Principal of the MGM College of Agricultural Biotechnology, Gandheli, Aurangabad for providing the facility and supporting the research work. Authors are also thankful to the faculty and the students for their help in designing and conducting the research experiments. Authors are grateful to Dr. D. Y. Patil Biotechnology and Bioinformatics Institute, Tathawade, Pune for providing necessary administrative support for Ph.D. work of Mr. A.V. Kharde.

\section{References}

Alfermann AW and Petersen M (1995) Natural product formation from plant cell biotechnology. Pl. Cell Tiss. Org. Cult. 43: 199-205.

Ali M, Abbasi BH and Haq IU (2013) Production of commercially important secondary metabolitesand antioxidant activity in cell suspension cultures of Artemisia absinthium L. Ind. Crop. Prod. 49: 400-406. 
Chaplot BB, Dave AM and Jasrai YT (2005) Bacopa monnieri (L.) Pennell: A Rapid, Efficient and Cost Effective Micropropagation. Pl. Tiss. Cult. Biotech. 15(2): $167-175$

Elangovan V, Govindasamy S, Ramamoorthy, N and Balasubramanian K (1995) In vitro studies on the anticancer activity of Bacopa monnieri. Fitoterapia. 66: 211-215.

Fowler MW and Scragg AH (1998) Plant Cell Biotechnology. NATO. ASI Series. Berlin, Springer Verlag, Germany. pp. 165-177.

Ikeuchi M, Sugimoto K and Iwase A (2013) Plant Callus: Mechanisms of induction and Repression. The Pl. Cell. 25: 3159-3173.

Jain M, Rajput R and Mishra A (2013) Enhancement of secondary metabolite biosynthesis in Bacopa monnieri: An in vitro study. Res. J. Rec. Sci. 2(1): 13-16.

Kala CP, Dhyani PP and Sajwan BS (2006) Developing the medicinal plants sector in northern India: Challenges and opportunities. J. Ethnobio. Ethnomed. 2: 32.

Kamonwannasit S, Phrompittayarat W, Ingkaninan K, Tanaka H and Putalun W (2008) Improvement of pseudojujubogenin glycosides production from regenerated Bacopa monnieri (L.) Wettst. and enhanced yield by elicitors. Z. Naturforsch. 63: 879-83.

Kharde AV, Chavan NS, Chandre MA, Autade RH and Khetmalas MB (2017) In vitro enhancement of bacoside in Brahmi (Bacopa monnieri) using colchicine. J. Pl. Biochem. Physiol. 5: 1-6.

Maraschin M, Sugui JA, Wood KV, Bonham C, Buchi DF, Cantao MP, Carobrez SG, Araujo PS, Peixoto ML, Verpoorte R and Fontana JD (2002) Somaclonal variation: A morphogenetic and biochemical analysis of Mandevilla velutina cultured cells. Braz. J. Med. Bio. Res. 35: 633-643.

Murthy HN, Lee EJ and Paek KY (2014) Production of secondary metabolites from cell and organ cultures: strategies and approaches for biomass improvement and metabolite accumulation. Pl. Cell Tiss. Org. Cult. 118: 1-16.

Mustafa NR, Winter WD, Iren FV and Verpoorte R (2011) Initiation, growth and cryopreservation of plant cell suspension cultures. Nat. Prot. 6: 715-742.

Naik PM, Manohar SH, Praveen N and Murthy HN (2010) Effects of sucrose and pH levels on in vitro shoot regeneration from leaf explants of Bacopa monnieri and accumulation of bacoside A in regenerated shoots. Plamt Cell Tiss. Org. Cult. 100: 235-239.

Naik PM, Manohar SH, Praveen N, Upadhya V and Murthy HN (2012) Evaluation of bacoside a content in different accessions and various organs of Bacopa monnieri (L.) Wettst. J. Herb. Sp. Med. Pl. 18: 387-395.

Panse VG and Sukhathme PV (1967) Statistical methods for agricultural workers, ICAR Publications, New Delhi.

Parale A, Barmukh R and Nikam T (2010) Influence of organic supplements on production of shoot and callus biomass and accumulation of bacoside in Bacopa monniera (L.) Pennell. Physiolo. Mol. Bio. Pl. 16(2): 167-175.

Phrompittayarat W, Putalun W, Tanaka H, Wittaya AS, Jetiyanon $\mathrm{K}$ and Ingkaninan $\mathrm{K}$ (2007) An enzyme-linked immunosorbant assay using polyclonal antibodies against bacopaside I. Ana. Chi. Acta. 584:1-6. 
Praveen N, Naik PM, Manohar SH, Nayeem N and Murthy HN (2009) In vitro regeneration of brahmi shoots using semisolid and liquid cultures and quantitative analysis of bacoside A. Acta. Physiol. Plantar. 31(4): 723-728.

Pravina K, Ravindra KR, Goudar KS, Vinod DR, Joshua AJ, Wasim P, Venkateswarlu K, Saxena VS and Amit A (2007) Safety evaluation of Baco Mind in healthy volunteers: A phase I study. Phytomed. 14: 301-308.

Rahman LU, Verma PC, Singh D, Gupta MM and Banerjee S (2002) Bacoside production by suspension cultures of Bacopa monnieri (L.) Pennell. Biotechnol. Let. 24: 1427-1429.

Rao RS and Ravishankar GA (2002) Plant cell cultures: Chemical factories of secondary metabolites. Biotechnol. Adv. 20: 101-153.

Russo A and Borrelli F (2005) Bacopa monniera, a reputed nootropic plant: An overview. Phytomed. 12: 305-317.

Saini N, Mathur R and Agrawal SS (2012) Qualitative and quantitative assesment of four marketed formulations of Brahmi. Ind. J. Pharm. Sci. 74(1): 24-28.

Sharma M, Ahuja A, Gupta R and Mallubhotla S (2014) Enhanced bacoside production in shoot cultures of Bacopa monnieri under the influence of abiotic elicitors. Nat. Prod. Res. pp. 1-5.

Shrivastava N and Rajani M (1999) Multiple shoot regeneration and tissue culture studies on Bacopa monnieri (L.) Pennell. Pl. Cell. Rep. 18: 919-923.

Talukdar A (2014) Biosynthesis of total bacosides in the callus culture of Bacopa monnieri. L. Pennell from North-east India. Int. J. Cur. Microbiol. Appl. Sci. 3(3): 140-145.

Tripathi N, Chouhan DS, Saini N and Tiwari S (2012) Assessment of genetic variations among highly endangered medicinal plant Bacopa monnieri (L.) from Central India using RAPD and ISSR analysis. Biotech. 2: 327-336.

Tripathi YB, Chaurasia S, Tripathi E, Upadhyaya A and Dubey GP (1996) Bacopa monniera Linn. As an antitoxidant: Mechanism of action. Ind. J. Exp. Biol. 34: 523-526. http://www.ccari.res.in/waspnew.html. 